\title{
CHANGES IN SPATIAL DISTRIBUTION AND INTERACTIONS OF TWO WOODY PLANTS DURING THE SANDY DESERTIFICATION PROCESS IN THE SOUTH MARGIN OF JUNGGAR BASIN, NORTHWEST CHINA
}

\author{
WANG, M. - JIANG, P. - NIU, P. X. - CHU, G. M. \\ Department of Forestry, Agricultural College, Shihezi University \\ Road of North 4th, Shihezi City, Xinjiang 832003, China \\ Corresponding author \\ e-mail:chgmxj@163.com
}

(Received $1^{\text {st }}$ Dec 2015; accepted $30^{\text {th }}$ Jul 2016)

\begin{abstract}
We examined the impact of plant-plant interactions and sandy desertification disturbance on population structure and spatial distribution of the two desert plant species Anabasis aphylla and Haloxylon ammodendron in the south margin of Junggar Basin, NW China. To explore species-habitat interactions, we compared the population structures of two woody plants and evaluated the growth of $A$. aphylla population in the different soil types. Furthermore, we used the Wiegand-Moloney $O$-ring statistic to study the spatial pattern and association of A. aphylla population and $H$. ammodendron population. We found some differences in the population structure and spatial distribution of A. aphylla and $H$. ammodendron with regard to the sandy desertification condition, which is also connected with changes in plant-plant interactions. Although an aggregation of $A$. aphylla and $H$. ammodendron population was found in each plot, the cause of spatial aggregation and association is different in the three sandy desertification areas. In the diluvial plot, the spatial association of A. aphylla and H. ammodendron seems to reflect a tense negative woody plant interaction. On the other hand, the random labeling null model showed that plant-plant interactions were largely determined by the combined effects of interspecific competition and harsh environments in the diluvial-sandy and sandy plots, contrary to the competitive effect of the early stage of sandy desertification expansion.
\end{abstract}

Keywords: $O$-ring function, population structure, desert plant, Haloxylon ammodendron, Anabasis aphylla

\section{Introduction}

Stand structure is known to interact with growth, survival, density, and spatial patterns to influence competition and demographic changes in a population (Huston and DeAngelis, 1987; Weiner and Damgaard, 2006). To a certain extent, stand structure determines habitat and species diversity and can be quantified to assess habitat quality for conservation purposes (Pommerening, 2002; Skov and Svenning, 2003). Thus, to understand plant communities, one needs to study the dynamic aspects of their stand structures (Harper, 1977; Mcintire and Fajardo, 2009), and these have rarely been documented for desert plants.

Spatial patterns of plants also are important characteristics of vegetation, and can play a significant role in ecological processes including competitive coexistence and transmission of mortality, and can have impacts that scale up to ecosystem-level processes (Alekseev and Zherebtsov, 1995; Arévalo and Fernández-Palacio, 2003). However, many factors play important roles in determining the spatial patterns of tree species distribution in a plant community. In general, biotic and abiotic factors may influence the distribution of species, and potentially control their abundance and promote coexistence (Zhang et al., 2010). Thus, some ecologists worked intensively to 
looking for the particular adaptations of each species to abiotic factors or for the complexity of species interactions (Hardy and Sonké, 2004), and has also successfully demonstrated that each species is restricted to a more or less wide range of habitats (Zhang et al., 2010). Furthermore, many species also exhibited ecological habitat preferences, although species numbers and associations are different among sites (Bazzaz, 1991). In addition, theoretical models also confirmed the coexistence of plant species based on habitat heterogeneity (Tilman and Pacala, 1993). Yet the influence of habitat heterogeneity on species coexistence is not fully understood. At present, our knowledge about species-habitat associations in other forests is insufficient, since most of the research is mainly focused on tropical forests (Condit et al., 2000). It would be important to extend the research to other forests (Chave, 2004), such as the speciessingle and habitat-complex desert vegetation where species-habitat associations and habitat preferences of some woody species are less considered.

The competition among plants affects the species composition and population structure of each species in a plant community (Greig-Smith, 1979; Stoll and Bergius, 2005). In general, the disproportionate sharing of resources causes size inequality among plants during the development of a mixed-species community (Weiner, 1985). Therefore, both intra- and interspecific competition should be considered to understand the dynamics of the component species (He and Duncan, 2000; Nishimura et al., 2002; Nishimura et al., 2005). Conversely, the spatial patterns of plants affect competition (Duncan, 1991; Hara et al., 1995; Kubota and Hara, 1995). Regular patterns have been historically viewed as the result of intense competition for limited resources, such as available water or soil resources (King and Woodell, 1973; Phillips and MacMahon, 1981; Skarpe, 1991). Intraspecific aggregation has been attributed to environmental heterogeneity (Schenk et al., 2003; Perry et al., 2009), seed dispersal (Schurr et al., 2004), and plant interactions (Phillips and MacMahon, 1981; Tirado and Pugnaire, 2003). In more arid communities, interspecific aggregation of forbs, grasses, and juvenile woody plants around larger shrubs and trees is often interpreted as evidence of facilitation (Brooker et al., 2008).

The present study describes stand structures and competitive interaction among plants dominated by two dominant desert species Anabasis aphylla and Haloxylon ammodendron in the south margin of Junggar Basin, NW China, and discusses the probability of coexistence of the two species via spatial partitioning. H. ammodendron has many xeromorphic characteristics of adapting to drought, salinity, poor nutrition, strong wind, sand movement, and high light intensity (Fahn and Cutler, 1992; Huang et al., 2003). As an important component of old Mediterranean flora, it widely spread in Junggar Basin, northeast of Tarim Basin and several other desert areas on a range of soils (Wu, 1980) and is a typical psammophytic species. However, A. aphylla population mainly distributes in diluvial fan, lowland among dunes, Gobi and hillside (Wu, 1980), and presents staggered distribution with $H$. ammodendron population in the desert-oasis ecotone (Guo et al., 2009). Now, spatial pattern and association of $A$. aphylla and $H$. ammodendron have many researches in Junggar basin (Song et al., 2010; Chu et al., 2014; Wang et al., 2014; Wang et al., 2015). But, the study on interspecific relation between $A$. aphylla and $H$. ammodendron have no report in three soil types.

The aim of this study was to analyze factors that determine the coexistence of the two desert woody plant species and infer the processes that form spatial patterns by describing the population structure, spatial distribution and plant-plant interactions of these species in three soil types in the southern margin of Junggar Basin, NW China. 
The $O$-ring statistic was used for point pattern analysis at various scales. One main questions is addressed: do the two dominant woody species in three soil habitat show an aggregated spatial distribution and plant-plant interaction ? This study could contribute to the understanding of species coexistence and diversity maintenance in temperate desert vegetation.

\section{Materials and methods}

\section{Study area}

The study area was located on the edge of diluvial fan spanning an elevation range of $258-279 \mathrm{~m}$ in the southern margin of Junggar Basin in Xinjiang $\left(45^{\circ} 22^{\prime} 43.4^{\prime \prime} \mathrm{N}\right.$, $84^{\circ} 50^{\prime} 32.5^{\prime \prime} \mathrm{E}$ ), from July to September 2010, which is a transitional zone from the diluvial fan to desert. Geological substrates of the study site include aeolian deposits sandy soil and highly eroded diluvial soil. The mean temperature past 20 years varies from 5 to $9^{\circ} \mathrm{C}$, minimum winter temperatures vary from -30 to $-41^{\circ} \mathrm{C}$ and maximum summer temperatures $30-40^{\circ} \mathrm{C}$. Snow melt at the end of winter, together with the rainfall, amounts to an annual precipitation of $100-150 \mathrm{~mm}$. In the study area, the vegetation cover ranges between $10 \%$ and $35 \%$. The woody vegetation is dominated by A. aphylla and $H$. ammodendron. A. aphylla is a semi-shrub (also known as subshrub or dwarf shrub) that hardly reaches heights above $85 \mathrm{~cm}$, while $H$. ammodendron is a subtree or large shrub that can reach heights exceeding $4 \mathrm{~m}$ in the study area. Other woody plant species in the area include Reaumuria soongorica, Nitraria roborowskii and Tamarix ramosissima, which is native species.

Both the disturbance stages and the intensity of sand burial should follow gradients along the wind direction. In August 2010, we elected three typical sample plots as the representative of a gradient to represent different desertification disturbance stages of the shrub communities along the main wind direction. P1 plot (1 ha) was laid out in an area with diluvial soil but with a small amount of small gravels and sandy soil is about $10 \%$ (referred to as "diluvial plot"). P1 plot sites at the middle slope position with a slope range of $7-15^{\circ}$ and encompasses more irregular ground surfaces such as depression and runnel. This plot was considered to represent a furthest area from the sand source. P2 plot (1 ha) was laid out in an area with ecotone or hierarchical distribution between diluvial and sandy soil (referred to as "diluvial-sandy plot"). Sandy soil area is about 55-65\% and sandy layer is 5-30 cm deep. P3 plot (1 ha) in an area with sandy soil and sandy layer is $20-200 \mathrm{~cm}$ (referred to as "sandy plot"). The microtopography of three plots is complicated and heterogeneous. The position of each plot was located by design for each of the three soil types and to cover representative stands of the two dominant woody plants in the area. The diluvial plot was $3.5 \mathrm{~km}$ from the diluvial-sandy plot and $4.6 \mathrm{~km}$ from the sandy plot and the sandy and diluvialsandy plots were $1.1 \mathrm{~km}$ apart.

\section{Methods}

\section{Data collection}

Each plot $(100 \times 100 \mathrm{~m})$ was divided into 400 contiguous $5 \times 5 \mathrm{~m}$ quadrates, as the basic unit of vegetation survey, using the DQL-1 forest compass (Harbin Optical Instrument Factory, China). All woody plants, including living and dead standing ones, were investigated. The species names, relative location of each individual, height, 
crown width (the greatest diameter of the vertical projection of the crown in two directions, i.e., north-south or east-west), microhabitat (e.g., soil surface, depression patch) were recorded.

\section{Classification of plant age classes}

Since spatial patterns at each growth stages suggest the past process of regeneration (Nanami et al. 2011), we classified A. aphylla plants based on reproductive ability, into seedlings ( $\leq 10 \mathrm{~cm}$ height), juveniles $(10<$ height $\leq 25 \mathrm{~cm})$, and adults $(>25 \mathrm{~cm}$ height $)$ while The population of H.ammodendro was divided into tree stages, i.e., seedlings ( $\leq$ $50 \mathrm{~cm}$ height $)$, juveniles $(50<$ height $\leq 100 \mathrm{~cm})$, adults $(>100 \mathrm{~cm}$ height $)$.

\section{Point pattern analysis}

Wiegand and Moloney (2004) developed a multiscale method called the $O$-ring statistic that is based on the $L$-function (Ripley, 1977). The $O$-ring statistic isolates specific distance classes by replacing the circles of Ripley's $K$-function with rings, and by using the mean number of neighbors in a ring of radius $r$ and ring width around an individual (Wiegand and Moloney, 2004). Consequently, the $O$-ring statistic has the additional advantage that it is a probability density function with the interpretation of a neighbourhood density, which is more intuitive than an accumulative measure (Stoyan and Pettinen, 2000). For $O$-ring statistic, the univariate statistic is used to analyze the spatial pattern of one object, while the bivariate statistic is used to analyze the spatial association of two objects (pattern 1 and pattern 2) (Wiegand and Moloney, 2004).

In this study, the univariate $O$-ring statistic was used to analyze the spatial patterns of different growth stages plants, and the bivariate $O$-ring statistic was used to analyze spatial associations among different growth stages in the three plots. For the univariate analyses we used the null model of complete spatial randomness (CSR) as a null hypothesis (Wiegand and Moloney, 2004; Getzin et al., 2008), because the spatial distributions of plants in the tree plots seem to be affected significantly by habitat heterogeneity (e.g., soil patch and micro topography). To test spatial independence of two size classes between the two species, we examined the spatial distribution of the tree size classes of two wood plants in relation to $H$. ammodendron and A. aphylla population with the independent null model (Wiegand and Moloney, 2004). For univariate analysis, if $O(r)$ above the upper confidence limit indicates aggregation, while $O(r)$ below the lower confidence limit indicates regularity. For bivariate analysis, if at a given distance $\mathrm{r}, O_{12}(r)$ is above the upper (or below the lower) limit of the confidence envelope, it indicates that growth stage 2 is positively (or negatively) associated with growth stage 1 at the distance r. $O_{12}(r)$ is within the confidence intervals, which indicates that there is no interaction between growth stage 1 and 2 .

Degree of sandy desertification in three sample plots leaded to plenty of dead standing plants and affectted population pattern. So, contrary to the two spatial approaches, we investigated the spatial relation between the distributions of dead standing plants and adult, the random labeling null model was used to detect possible differences in the spatial distribution of dead standing plants compared to the distribution of adult plants regardless of the underlying first-order process (Wiegand and Moloney, 2004). Random labelling has not been frequently used in forestry research, but it has been implicitly used to assess "random mortality", considering labels as the live and dead standing plants categories (Kenkel, 1988). We used the case- 
control design with living plants of A. aphylla or H. ammodendron as pattern 1 (control pattern) and $A$. aphylla dead standing plants as pattern 2 (cases) (Getzin et al., 2008; Wiegand and Moloney, 2004). Thus, a difference of $g_{12}(r)$ and $g_{11}(r)$ provides insights into the spatial distribution of $A$. aphylla dead standing plants around living plants of $A$. aphylla or $H$. ammodendron in relation to the spatial distribution of living plants to each other (Getzin et al., 2008; Schleicher et al., 2011). The second comparison, $g_{12}(r)-$ $g_{11}(r)$, can be used to evaluate the spatial distribution of dead standing plants. For example, a positive deviation would mean that dead standing plants exhibited an aggregated spatial distribution in comparison to adult plants (Getzin et al., 2006; Getzin et al., 2008; Schleicher et al., 2011). To perform the random labeling analysis, the spatial position of all plants in the plot remained fixed, but the labels of the points (living plants or dead standing plants) were randomly assigned to the overall pattern (Bailey and Gatrell, 1995).

In addition, all data were tested for normality using a Shapiro-Wilks test. If the Kolmogorov-Smirnov test showed differences between the size-frequency distributions $(p<0.05)$, we used the Student's t-test (normally distributed values) or the MannWhitney U-test (if values were not normally distributed) to examine the difference in the mean tree-crown diameter of three tree height $(20 \mathrm{~cm}, 40 \mathrm{~cm}$ and $70 \mathrm{~cm})$ of A. aphylla population in the diluvial and diluvial-sandy plots and/or pattern aggregation intensity of each woody plant between plots.

\section{Results}

\section{Population structures of A. aphylla and H. ammodendron}

The diluvial and sandy plots were mostly occupied by $A$. aphylla and $H$. ammodendron, while the two species were co-dominant in the diluvial-sandy plot (Table 1, Fig. 1). In addition, the remaining 4 woody species accounted for less than $6 \%$.

In the sandy plot, $H$. ammodendron showed the highest density, the tallest mean height, and the largest mean tree-crown (Table 1, Fig. 1). In the three plots, the density of dead standing population of $A$. aphylla were 431, 1372 and 809 respectively, while those of of $\mathrm{H}$. ammodendron were fewer (Table 1). In addition, the $\mathrm{H} 20$ and $\mathrm{H} 40$ height A. aphylla grew bigger (mean tree-crown diameter) in the diluvial plot than the diluvial-sandy plot (Fig. 2; Manne-Whitney: $p<0.05$ ).

Table 1. Basic feature of two woody plants in the three study plots

\begin{tabular}{clccccc}
\hline Plots & \multicolumn{1}{c}{ Species } & $\begin{array}{c}\text { Mean height } \\
(\mathbf{c m})\end{array}$ & $\begin{array}{c}\text { Mean tree- } \\
\text { crown } \\
\text { (cm) }\end{array}$ & $\begin{array}{c}\text { Living plants } \\
\text { density } \\
\text { (individual / } \\
\text { ha) }\end{array}$ & $\begin{array}{c}\text { Dead } \\
\text { standing } \\
\text { plants density } \\
\text { (individual } / \\
\text { ha) }\end{array}$ & $\begin{array}{c}\text { Coverage } \\
(\%)\end{array}$ \\
\hline \multirow{2}{*}{ P1 } & A. aphylla & $49.56 \pm 23.65 \mathrm{~d}$ & $61.93 \pm 23.12 \mathrm{~d}$ & $6163 \pm 247 \mathrm{a}$ & $431 \pm 36 \mathrm{c}$ & $18.55 \pm 3.45 \mathrm{~b}$ \\
& H. mmodendron & $59.89 \pm 55.32 \mathrm{c}$ & $67.83 \pm 54.58 \mathrm{c}$ & $237 \pm 50 \mathrm{e}$ & $12 \pm 5 \mathrm{f}$ & $0.86 \pm 0.28 \mathrm{~d}$ \\
P2 & A. aphylla & $47.68 \pm 17.15 \mathrm{e}$ & $55.25 \pm 22.89 \mathrm{e}$ & $4372 \pm 359 \mathrm{~b}$ & $1372 \pm 315 \mathrm{a}$ & $10.48 \pm 4.16 \mathrm{c}$ \\
& H. mmodendron & $88.21 \pm 86.68 \mathrm{~b}$ & $107.54 \pm 68.06 \mathrm{~b}$ & $1262 \pm 104 \mathrm{~d}$ & $106 \pm 17 \mathrm{~d}$ & $11.46 \pm 5.62 \mathrm{c}$ \\
P3 & A. aphylla & $50.82 \pm 13.12 \mathrm{~d}$ & $61.15 \pm 15.10 \mathrm{de}$ & $74 \pm 17 \mathrm{f}$ & $809 \pm 112 \mathrm{~b}$ & $0.22 \pm 0.09 \mathrm{e}$ \\
& H. mmodendron & $159.41 \pm 65.10 \mathrm{a}$ & $115.68 \pm 60.49 \mathrm{a}$ & $2961 \pm 215 \mathrm{c}$ & $25 \pm 9 \mathrm{e}$ & $31.10 \pm 5.14 \mathrm{a}$ \\
\hline
\end{tabular}

a-f Means within a column at each treatment with the same letter are not significantly different $(P>0.05)$. 

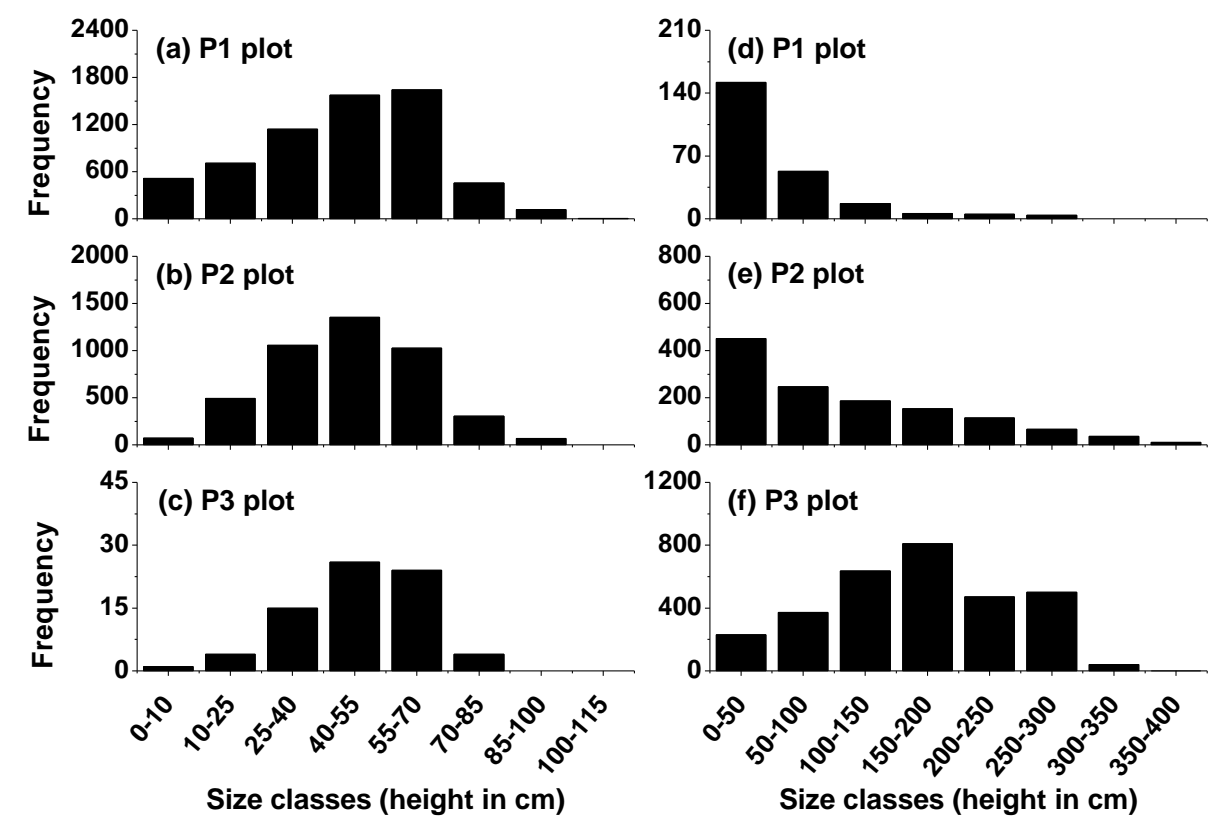

Figure 1. Height class distribution of A. aphylla $(a-c)$ and H. ammodendron $(d-f)$ in the three study plots

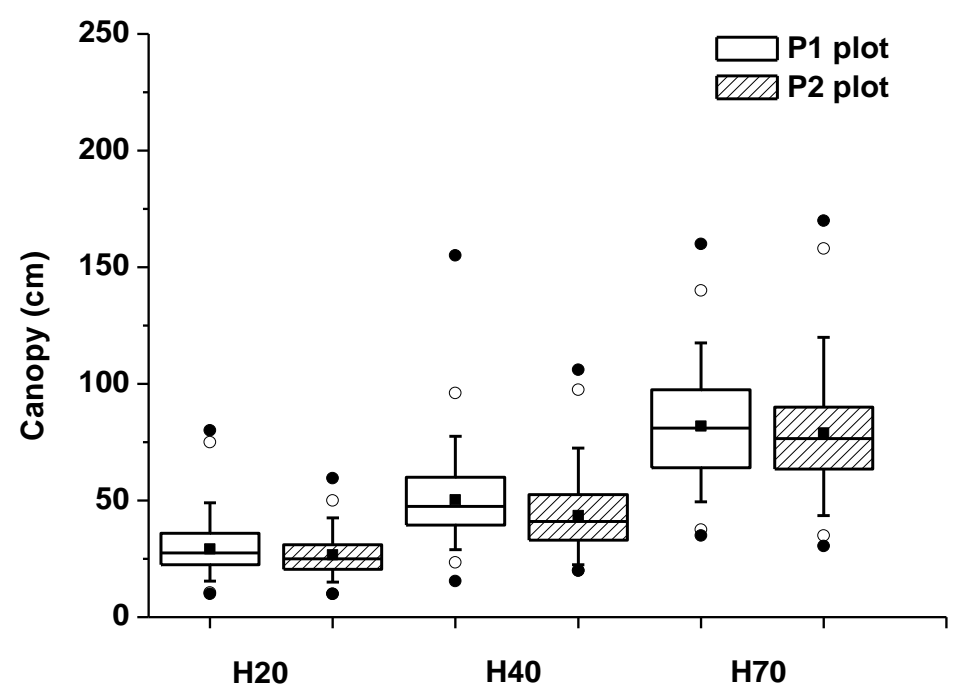

Figure 2. Mean tree-crown diameter of three tree height A. aphylla in the diluvial and diluvialsandy plot. Horizontal lines are the medians and the boxes spanning the first and third quartile, whiskers show the non-outlier range, whereas points are outliers. H2O, $H 40$ and $H 70$ are $20 \mathrm{~cm}$, $40 \mathrm{~cm}$ and $70 \mathrm{~cm}$ height of $A$. aphylla, respectively.

\section{Spatial pattern}

Analysis of the spatial pattern of A. aphylla population showed that plants in the diluvial and diluvial-sandy plots were significantly aggregated at all distances between 0 and $53 \mathrm{~m}$, while plants in the sandy plot was weakly aggregated at 1-34 $\mathrm{m}$ and $42-44$ 
$\mathrm{m}$, and randomly distributed at $0-1 \mathrm{~m}$ (Fig. 3a, b, c). A. aphylla population in the diluvial and diluvial-sandy plots tended to similar spatial distribution, but the difference between the aggregated intensity of two populations was striking (Fig. 3a, b; ManneWhitney: $p<0.05)$ while the difference of aggregated intensity between these two and the sandy plot was significant (Fig. 3a, b, $c$; Manne-Whitney: $p<0.05$ ).
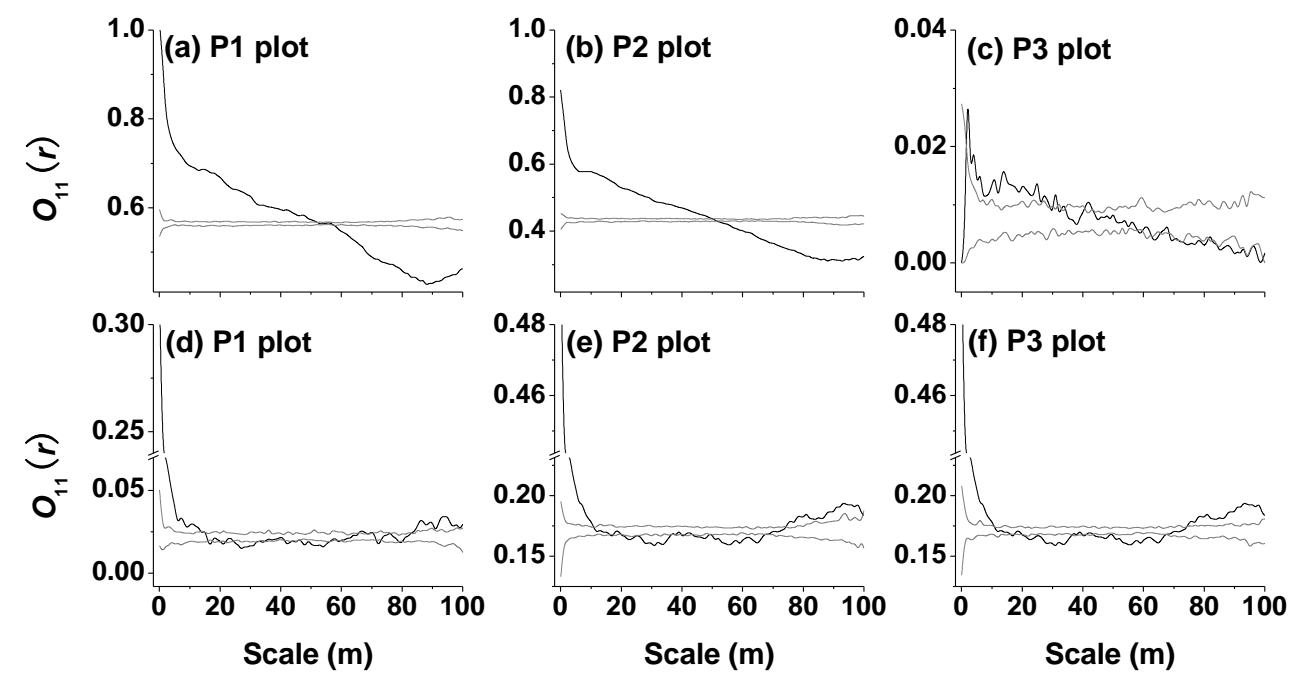

Figure 3. Spatial aggregation of A. aphylla population $(a-c)$ and $H$. ammodendron population $(d-f)$ in the three study plots analyzed by the univariate $O$-ring statistics with the null model of complete spatial randomness (CSR)

Analysis of the spatial pattern of $H$. ammodendron population indicated that plants in the diluvial, diluvial-sandy and sandy plots were significantly aggregated at $0-14 \mathrm{~m}, 0$ $12 \mathrm{~m}$ and $0-12 \mathrm{~m}$ respectively at small scale level (Fig. $3 d, e, f)$. H. ammodendron population in the three plots tended to similar spatial distribution, and the difference of aggregated intensity between the diluvial-sandy and sandy plots was not significant (Fig. 3e, f; Kolmogorov-Smirnov: $p>0.05$ ) while the difference of aggregated intensity between these two and the diluvial plot was significant (Fig. 3d, e, f; KolmogorovSmirnov: $p<0.05)$.

\section{Plant-plant interactions}

In the diluvial plot, $A$. aphylla population was negatively associated to $H$. ammodendron population at 0-55 m (Fig. 4a). A. aphylla and H. ammodendron population was a mostly negative association at $0-4 \mathrm{~m}, 6-16 \mathrm{~m}$ and $31-53 \mathrm{~m}$ in the diluvial-sandy plot (Fig. 4b). However, A. aphylla population was positively associated to $H$. ammodendron population at $0-51 \mathrm{~m}$ in the sandy plot (Fig. $4 \mathrm{c}$ ).

In the diluvial plot, seedlings and adults of $A$. aphylla were all spatially independent association at $0-1 \mathrm{~m}$ and had respectively negative association at $1-53 \mathrm{~m}$ and $1-55 \mathrm{~m}$ with $H$. ammodendron (Fig. $5 a, c$ ). Juveniles of $A$. aphylla and $H$. ammodendron were spatially independent at $0-12 \mathrm{~m}$ and had significantly negative association at $12-62 \mathrm{~m}$ (Fig. 5b). In the diluvial-sandy plot, seedlings of $A$. aphylla had positive association at 2-8 $\mathrm{m}$ and 18-26 m with H. ammodendron (Fig. 5d). Juveniles of A. aphylla had positive association at $0-32 \mathrm{~m}$ and $35-38 \mathrm{~m}$ with $H$. ammodendron (Fig. 5e). But, 
adults of $A$. aphylla and $H$. ammodendron were spatially negative association at 1-54 $\mathrm{m}$ (Fig. 5f). In the sandy plot, seedlings of A. aphylla were spatially independent association at all scales, and juveniles and adults of $A$. aphylla were all positive association with $H$. ammodendron at small scales (Fig. $5 g, h, i$ ).
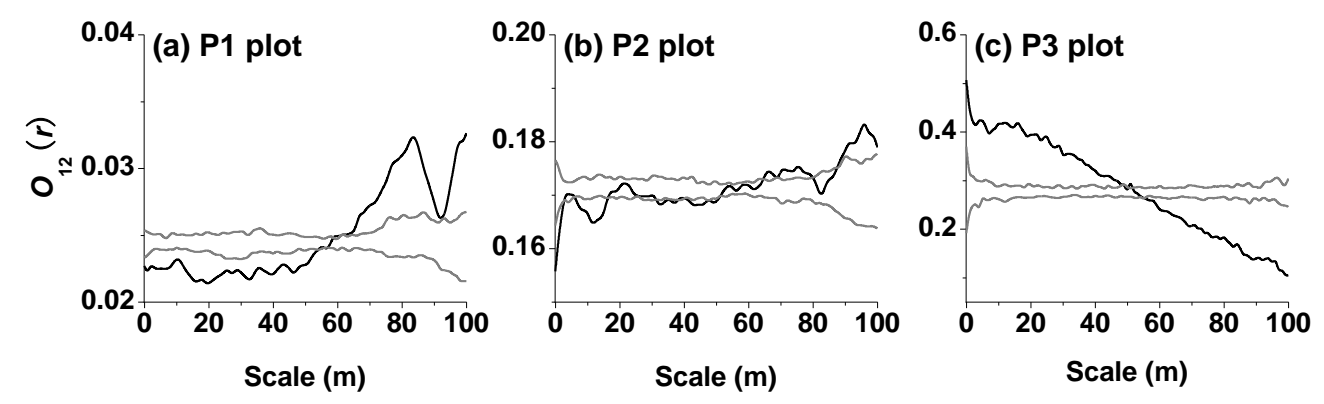

Figure 4. Spatial association between A. aphylla population and H. ammodendron population in the three study plots with the null model of independence.
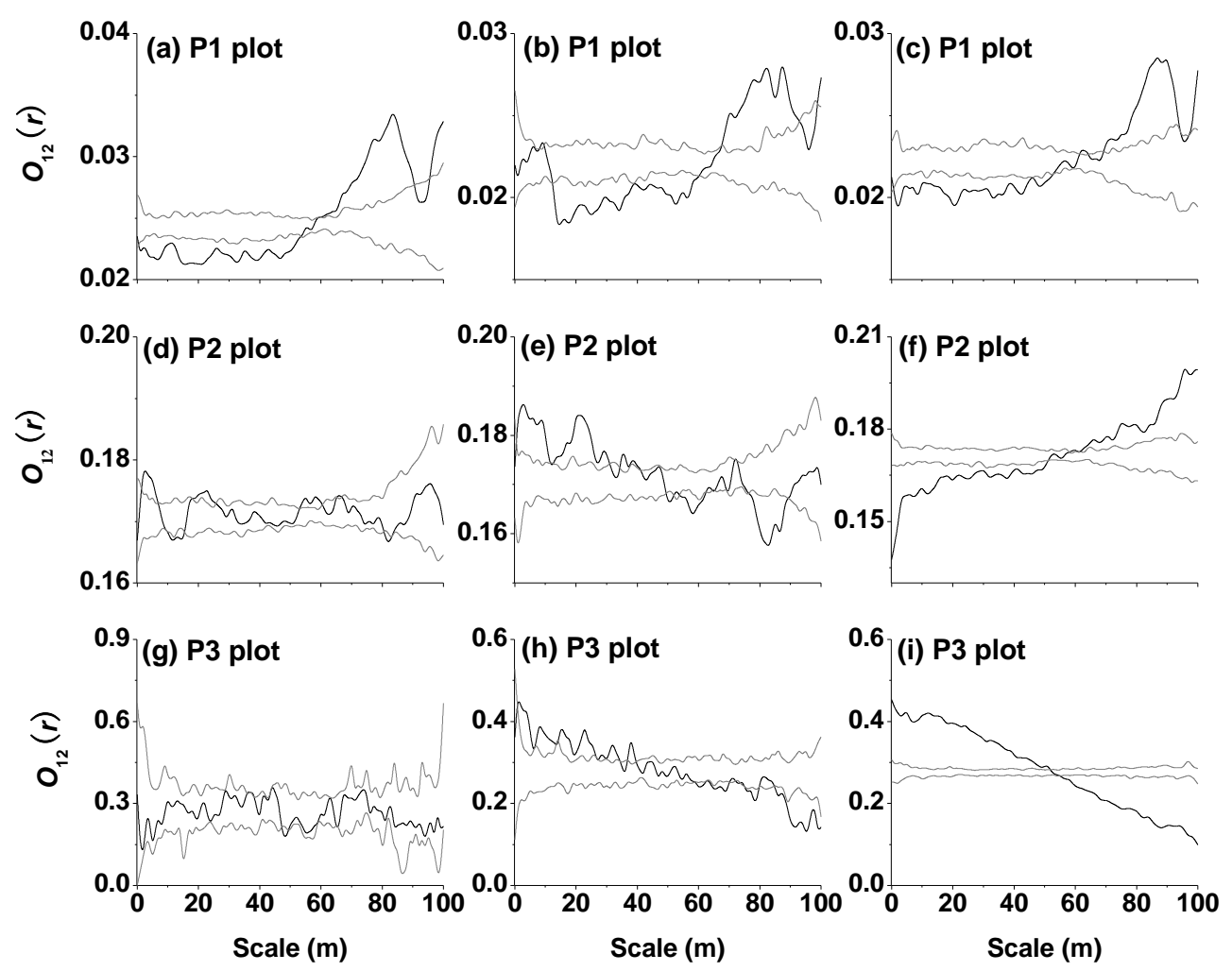

Figure 5. Spatial association between different stages of A. aphylla population and $H$. ammodendron population in the two study plots with the null model of independence. Seedlings of A. aphylla-H. ammodendron ( $a, d, g)$; Juveniles of A. aphylla-H. ammodendron $(b, e, h)$; Adults of A. aphylla-H. ammodendron $(c, f, i)$. 


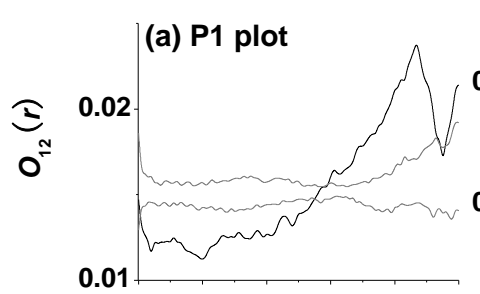

(d) P2 plot
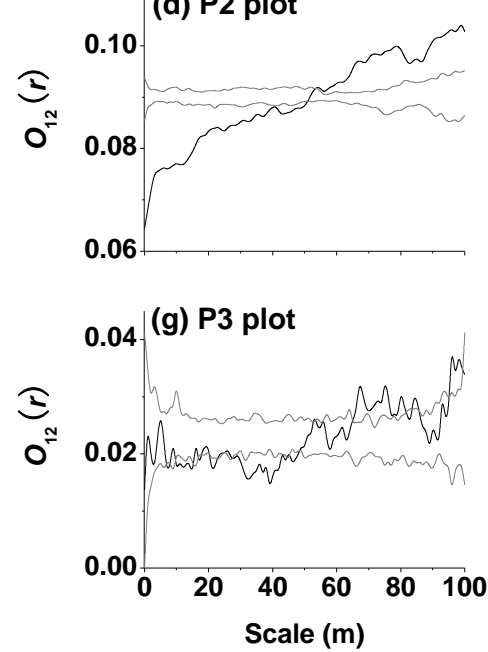

(b) P1 plot
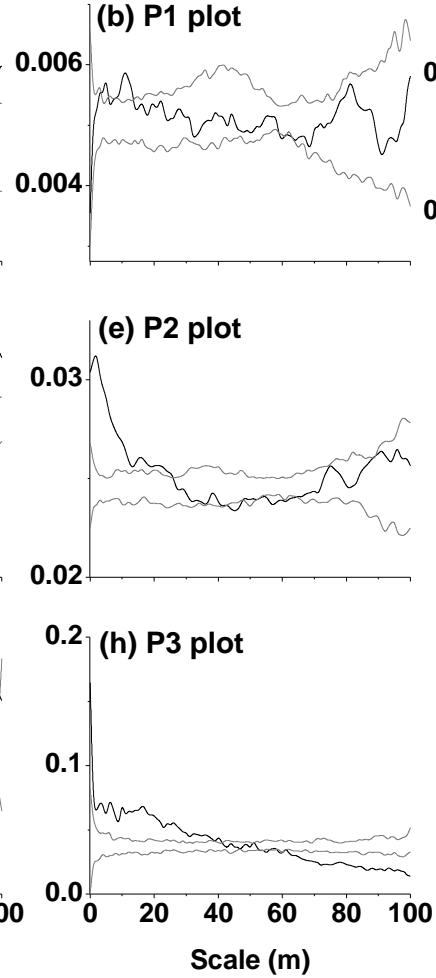

(c) P1 plot
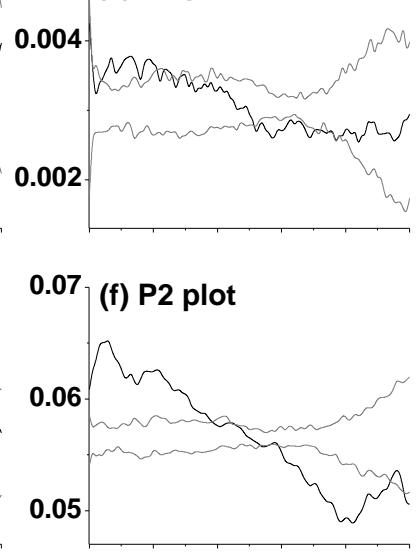

0.4 (i) P3 plot

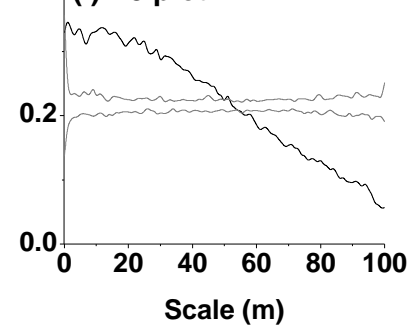

Figure 6. Spatial association between different stages of H. ammodendron population and A. aphylla population in the three study plots with the null model of independence. Seedlings of $H$. ammodendron-A. aphylla $(a, d, g)$; Juveniles of $H$. ammodendron-A. aphylla $(b, e, h)$; Adults of H. ammodendron-A. aphylla $(c, f, i)$.
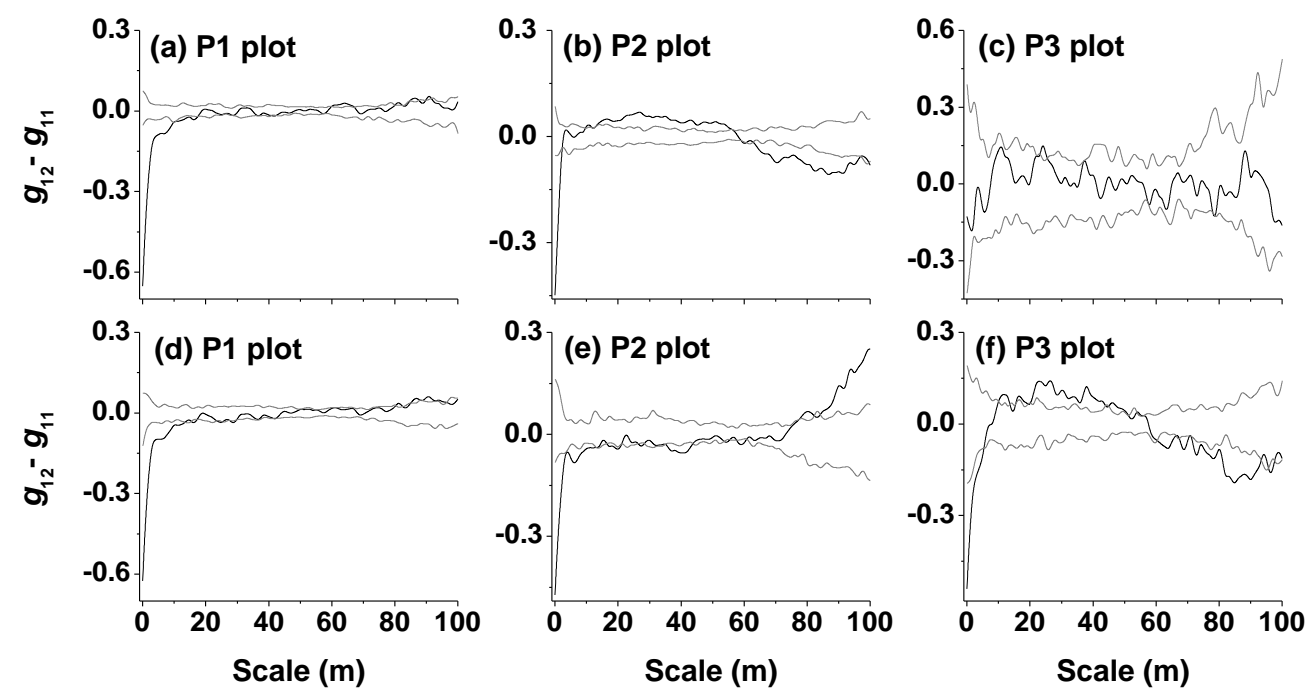

Figure 7. Spatial association between dead standing population of A. aphylla and living population in the three study plots with the null model of random labeling. A. aphylla-Dead standing population of A. aphylla $(a, b, c)$; H.ammodendro-Dead standing population of A. aphylla $(d, e, f)$. 
In the diluvial plot, seedlings of $H$. ammodendron had significantly negative association at $0-56 \mathrm{~m}$ with A. aphylla (Fig. 6a). Juveniles and adults of $H$. ammodendron had respectively positive association at 4-14 $\mathrm{m}$ and 5-23 $\mathrm{m}$ with $A$. aphylla (Fig. 6b, c). In the diluvial-sandy plot, seedlings of $H$. ammodendron and $A$. aphylla were spatially negative association at 0-53 $\mathrm{m}$ (Fig. 6d). Juveniles and adults of $H$. ammodendron had respectively positive association at $0-27 \mathrm{~m}$ and $0-39 \mathrm{~m}$ with $A$. aphylla (Fig. 6e, $f$ ). In the sandy plot, seedlings of $H$. ammodendron tended to be no association with $A$. aphylla within a small scale(Fig. $6 g$ ). Juveniles and adults of $H$. ammodendron had respectively positive association at $0-39 \mathrm{~m}$ and $0-54 \mathrm{~m}$ with $A$. aphylla (Fig. 6h, i).

For dead standing plants of $A$. aphylla in the diluvial plot, the test statistic $g_{12}(r)-$ $g_{11}(r)$ differed respectively and significantly from the random labeling null model at $0-9$ $\mathrm{m}$ and $0-16 \mathrm{~m}$, indicating an additional aggregation of dead standing plants of $A$. aphylla independent of $A$. aphylla and H. ammodendron pattern (Fig. $7 a, d$ ). In the diluvial-sandy plot, the test statistic $g_{12}(r)-g_{11}(r)$ revealed strong departures from random labeling pointing to an aggregation mechanism of dead standing plants of $A$. aphylla independent of $A$. aphylla and $H$. ammodendron pattern at $0-1 \mathrm{~m}$ and $0-45 \mathrm{~m}$ respectively $(F i g .7 b, e)$. In the sandy plot, there was a very strong aggregation among dead standing plants independent from dead standing plants of $A$. aphylla and $H$. ammodendron living plants relation at 0-7 m and 54-92 $\mathrm{m}$, while dead standing plants of $A$. aphylla and $A$. aphylla living plants were no association spatially (Fig. $7 c, f$ ).

\section{Discussion}

\section{Spatial pattern}

Aggregation is a very general phenomenon in plants, it can often be explained simply in terms of regeneration near to seed sources, or perhaps in safe sites associated with older, larger individuals of one's own or another species (Zhang et al., 2010; Schleicher et al., 2011). We suggest that the small scale aggregation in the A. aphylla and $H$. ammodendron populations were an effect of limited seed dispersal because of winged perianth being separated arfter a short retention, and the safe-site effect probably plays an important role. At medium scales, H. ammodendron population was deviated from aggregated distribution. Moreover, the similar spatial distribution of $H$. ammodendron was exhibited in the four habitats by Song et al. (2010). H. ammodendron owns enormous root system and capacity of the drought resistance, which probably lead to the no aggregated spatial distribution of $H$. ammodendron population at medium scales. What is more, $H$. ammodendron has a longer lifespan, which allows them to outlive $A$. aphylla, so that the spatial pattern of $H$. ammodendron population is more stable (Song et al., 2010). However, A. aphylla population was still aggregated in the diluvial and diluvial-sandy plots at medium scales. It's worth mentioning that Phillips and MacMahon (1981) found a trend which small shrubs tended to be aggregated, mediumsized shrubs randomly distributed, and large shrubs regularly distributed in spatial patterns of desert shrubs. For A. aphylla, non-overlapping individuals are constrained to occur in regular-looking distributions, but this appearance of regularity may conceal significant aggregation (Prentice and Werger, 1985). We inferred that the effect of intraspecific competition of $A$. aphylla was expressed as the underground part interactions and the dwarf performance tolerating drought stress. Furthermore, $A$. aphylla continued to maintain aggregated state of population and promoted cycle 
succession due to the group effect. In addition, we suggested that the inherent spatial distribution of $A$. aphylla in the sandy plot did not exist and the aggregated intensity in the diluvial-sandy plot was greatly reduced due to the change of harsh desert environment and interspecific competition.

\section{Spatial association}

As an important natural selection pressure of plant distribution in desert areas, desertification plays an important role on the community succession (Maun, 1998; Peng et al., 2012; Salvati et al., 2008). Some studies showed that sand burial can enhance the seed germination and seedling emergence of the sand-burial tolerant shrubs (Zhang et al., 2010; Wang et al., 2013). During the process of wind and sandy disturbance in Junggar Basin shrub communities, strongly sand-burial tolerant shrub $H$. ammodendron plays a expand role after sand invasion while the occurrence of weekly sand-burial tolerant shrub $A$. aphylla was gradually reduced. Therefore, $H$. ammodendron and $A$. aphylla exhibited a significant negative association at small scales at the early stage of desertification expansion (diluvial plot), and tended to negative association at the intermediate stage of desertification expansion (diluvial-sandy plot). However, $H$. ammodendron and $A$. aphylla had a significant positive association at small scales at the later stage of desertification expansion (sandy plot). We suggested that weakly sandburial tolerant specie A. aphylla tended to become extinct, and the number of $H$. ammodendron increased at the later stage of desertification. The competition association between the two woody species was weaker at small scales because A. aphylla was sparsely distributed in the sandy plot. Furthermore, we found that small size plants of $A$. aphylla in the diluvial-sandy plot were smaller than those in the diluvial plot while $H$. ammodendron plant number in the diluvial-sandy and sandy plots were bigger than those the diluvial plot. This suggested that sand layer thickness seems to play an important role in the growth of two woody plants, and a negative effect of $H$. ammodendron population in the diluvial-sandy and sandy plots cannot be excluded for A. aphylla population.

In semi-arid and arid area, water is often the most limiting resource (Sheng et al., 2004). Small scale variation in vegetation, soil surface cover, and soil texture, alters the amount of water available to plants (Whitford, 2003; Zou et al., 2010). In sandy soil, there should be more moisture content for desert plant than in finer-textured clay soils due to the high infiltration rate, deep percolation, and less evaporation of capillary water in coarse soil (McAuligge, 1994; Zou et al., 2010). For a corresponding life form, $H$. ammodendron developed more feeder roots in sandy compared to heavy textured soil, showing that plants at coarse soil have a greater need to develop more roots (Zou et al., 2010). Sheng et al. (2004) found root lengths up to $13.5 \mathrm{~m}$ of $H$. ammodendron in the sandy soils and we also observed root lengths of $H$. ammodendron greater than $8 \mathrm{~m}$ in the sandy soils. As a large size plant in Junggar Basin, H. ammodendron may deplete the water and nutrient resources of the soil beyond their tree-crown areas because of a large root system in the sandy soil area. However, with a large number of small size plants growth, we expect that $H$. ammodendron will have a larger root system extent in the diluvial-sandy soil area. A belowground negative effect of $H$. ammodendron on $A$. aphylla population may occur in the desertification area. In addition, Cao et al. (2005) reported that the niche breadths of most original species decreased and those of psammophytic species increased accordingly in the process of desertification. Therefore, this difference in density of the desert species can be caused by (1) niche 
differences, $H$. ammodendron preferred sandy soil and A. aphylla preferred diluvial soil and (2) a competitive effect, in which $H$. ammodendron may be a stronger competitor on the desertification soil than A. aphylla.

In addition, plants pass through different physiological stages as their development progresses and competition occurs not only within species, but also within and between stages of different species (Mangla et al., 2011). Seedlings stage may be particularly sensitive to environment and neighboring individual, and much more sensitive to competition than adult plants (Foster, 1999; Suding and Goldberg, 1999). In our study, $H$. ammodendron population (superior competitor) was similar to the conclusions while seedlings of $A$. aphylla and $H$. ammodendron population changed from negative association to no or even positive association in desertification process. Competition during early stages of growth can critically influence individual plant growth and determine future development patterns (Foster and Gross, 1998; Suding and Goldberg, 1999). Small differences in initial size and growth rates between individuals and species could potentially determine long-term developmental patterns (Mangla et al., 2011). In the field, annual growth of $A$. aphylla was about $4 \mathrm{~cm}$ far less than $H$. Ammodendron (Wang and $\mathrm{Chu}, 2014$ ). We suggested that capability of fast growth by $H$. ammodendron, especially during the early growth phase, allows them to capture more resources (e.g., water) than slow growing A. aphylla. This provides $H$. ammodendron a competitive advantage in later stages of growth compared to A. aphylla. Thus, seedlings of $H$. ammodendron have potential competitive power in desertification process.

\section{Shift of plant-plant interactions among the sandy desertification stages}

Intraspecific and interspecific interactions determine the structure and dynamics of ecological communities and their responses to environmental change (Mangla et al., 2011). Nanami et al. (2011) also suggested the shift between interspecific and intraspecific competition corresponded to the change in the spatial association between the two species. In the diluvial plot, $H$. ammodendron was repulsive with the lifehistory stage of A. Aphylla at relative small or medium scale. Furthermore, the random labeling null model showed that the aggregation of dead standing plants of A. aphylla was strong around $A$. aphylla and $H$. ammodendron plants, indicating intense intraspecific and interspecific competition in the diluvial plot. Classical competition theory predicts intraspecific competition should be greater than interspecific competition because individuals of the same species share similar resource requirements (Fowler, 1986, Goldberg and Barton, 1992). The theory may exist in the early sandy desertification stages for A. aphylla. But, the aggregation scales of dead standing plants of $A$. aphylla was small or even zero around $A$. aphylla while was above $7 \mathrm{~m}$ around $H$. ammodendron at the intermediate and later stage of desertification expansion. Interestingly, seedlings and Juveniles of A. aphylla were non-negative association or even positive association with $H$. ammodendron plants in the diluvial-sandy plot, and all tree age stages of diluvial-sandy plot tended to be non-negative association with $H$. ammodendron plants in the sandy plot. $H$. ammodendron also may create spatial refuges for some or all growth stages of A. aphylla with environmental change. We suggested that the dead standing plants of A. aphylla mainly caused by interspecific and intraspecific competition in the diluvial plot, and were largely determined by the combined effects of interspecific competition and harsh environments in the diluvialsandy and sandy plots. Thus, the interspecific competition changes depending on the 
shift of spatial environment (desertification) between the two species, suggesting that the intraspecific and interspecific competition and spatial patterns are interdependent.

\section{Conclusion}

In sum, in our study area, we found clear differences in the population density and spatial distribution of $A$. aphylla and $H$. ammodendron with regard to the desertification condition, which is also connected with changes in plant-plant interactions. Although an aggregation of $A$. aphylla and $H$. ammodendron population was found in each plot, the cause of spatial aggregation and association is different in the three sandy desertification areas. In the diluvial plot, the spatial association of $A$. aphylla and $H$. ammodendron seems to reflect a tense negative woody plant interaction. On the other hand, the random labeling null model showed that plant-plant interactions were largely determined by the combined effects of interspecific competition and harsh environments in the diluvial-sandy and sandy plots, contrary to the competitive effect of the early stage of desertification expansion. In addition, Seedlings stage may be particularly sensitive to environment and competition in our study sites, and we also revealed the competitive advantage of $H$. ammodendron seedlings and therefore its potential for encroachment with the desertification environment. It is clear that competition between $H$. ammodendron and A. aphylla influence structure, pattern, and dynamics of plant distributions, but the relative role of competition may vary dramatically among different desertification disturbance.

Acknowledgements. The research is supported by the Program of National Natural Science Foundation of China (31360170, 31460187, 31570595) and the Cultivation Program of Young Scientific and Technologic Talent of Shihezi University (2013ZRKXYQ11).

\section{REFERENCES}

[1] Alekseev, A. S., Zherebtsov, R. R. (1995): Regularities of spatial distribution of damaged vegetation under conditions of regional and local air pollution (with reference to the impact zone around the Pechenganikel mining and smelting plant). - Russian Journal of Ecology 26: 428-435.

[2] Arévalo, J. R., Fernández-Palacios, J. M. (2003): Spatial patterns of trees and juveniles in a laurel forest of Tenerife, Canary Islands. - Plant Ecology 165: 1-10.

[3] Bailey, T. C., Gatrell, A. C. (1995): Interactive spatial data analysis. - Longman Group Limited, Essex.

[4] Bazzaz, F. A. (1991): Habitat selection in plants. - The American Naturalist 137: 116130.

[5] Brooker, R. W., Maestre, F. T., Callaway, R. M., Lortie, C. L., Cavieres, L. A., Kunstler, G., Liancourt, P., Tielbörger, K., Travis, J. M. J., Anthelme, F., Armas, C., Coll, L., Corcket, E., Delzon, S., Forey, E., Kikvidze, Z., Olofsson, J., Pugnaire, F., Quiroz, C. L., Saccone, P., Schiffers, K., Seifan, M., Touzard, B., Michalet, R. (2008): Facilitation in plant communities: the past, the present, and the future. - Journal Ecology 96: 18-34.

[6] Cao, C. Y., Zhu, D. H., Geng, L. (2005): Plant species diversity changes of Caragana microphylla pasture in process of desertification. - Journal of Soil and Water Conservation 19: 166-169. (in Chinese with an English summary).

[7] Chave, J. (2004): Neutral theory and community ecology. - Ecology Letters 7: 241-253. 
[8] Chu, G. M., Wang, M., Zhang, S. X. (2014): Spatial patterns and associations of dominant woody species in desert-oasis ecotone of South Junggar Basin, NW China. Journal of Plant Interactions 9(1): 738-744.

[9] Condit, R., Ashton, P. S., Baker, P., Bunyavejchewin, S., Gunatilleke, S., Gunatilleke, N., Hubbell, S., Foster, R., Itoh, A., LaFrankie, J. V., Lee, H. S., Manokaran, L. E. N., Sukumar, R., Takuo, Y. T. (2000): Spatial patterns in the distribution of tropical tree species. - Science 288: 1414-1418.

[10] Duncan, R. P. (1991): Competition and the coexistence of species in a mixed podocarp stand. - Journal of Ecology 79: 1073-1084.

[11] Fahn, A., Cutler, D. F. (1992): Xerophytes. Handbuch der Pflanzenanatomie. Spezieller Teil, Band XIII, Teil 3. - Gebrüder Borntraeger, Berlin.

[12] Foster, B. L. (1999): Establishment, competition and the distribution of native grasses among Michigan old-fields. - Journal Ecology 87: 476 - 489.

[13] Foster, B. L., Gross, K. L. (1998): Species richness in a successional grassland: effects of nitrogen enrichment and plant litter. - Ecology 79: 2593-2602.

[14] Fowler, N. (1986): The role of competition in plant communities in arid and semiarid regions. - Annu Rev Ecol Syst 17: 89-110.

[15] Getzin, S., Wiegand, T., Wiegand, K., Getzin, S., Wiegand, T., Wiegand, K., He, F. L. (2008): Heterogeneity influences spatial patterns and demographics in forest stands. Journal of Ecology 96: 807-820.

[16] Getzin, S., Dean, C., He, F. L., Trofymow, J. A., Wiegand, K., Wiegand, T. (2006): Spatial patterns and competition of tree species in a Douglas-fir chronosequence on Vancouver Island. - Ecography 29: 671-682.

[17] Goldberg, D. E., Barton, A. M. (1992): Patterns and consequences of interspecific competition in natural communities: a review of field experiments with plants. -The American Naturalist 139: 771-801.

[18] Greig-Smith, P. (1979): Pattern in vegetation. - Journal Ecology 67: 755-779.

[19] Guo, Q. S., Cong, Z. F., Wang, C. L. (2009): Study on ecology of Haloxylon ammodendron and Cistanche deserticola Ma. - Science Press, Beijing. (in Chinese).

[20] Hara, T., Nishimura, N., Yamamoto, S. (1995): Tree competition and species coexistence in a cool-temperate old-growth forest in southwestern Japan. - Journal of Vegetation Science 6: 565-574.

[21] Hardy, O. J., Sonké, B. (2004): Spatial pattern analysis of tree species distribution in a tropical rain forest of Cameroon: assessing the role of limited dispersal and niche differentiation. - Forest Ecology and Management 197: 191-202.

[22] Harper, J. L. (1977): Population biology of plants. - Academic Press, London.

[23] He, F., Duncan, R. P. (2000): Density-dependent effects on tree survival in an old-growth Douglas fir forest. - Journal Ecology 88: 676-688.

[24] Huang, Z. Y., Zhang, X. S., Zheng, G. H., Gutterman, Y. (2003): Influence of light, temperature, salinity and storage on seed germination of Haloxylon ammodendron. Journal of Arid Environment 55: 453-464.

[25] Huston, M. A., DeAngelis, D. L. (1987): Size bimodality in monospecific populations: a critical review of potential mechanisms. - The American Naturalist 129: 678-707.

[26] Kenkel, N. C. (1988): Pattern of self-thinning in jack pine: testing the random mortality hypothesis. - Ecology 69: 1017-1024.

[27] King, T. J., Woodell, S. R. J. (1973): The causes of regular pattern in desert perennials. Journal of Ecology 61: 761-765.

[28] Kubota, Y., Hara, T. (1995): Tree competition and species coexistence in a sub-boreal forest, northern Japan. - Annals Botany 76: 503-512.

[29] Mangla, S., Sheley, R. L., James, J. J., Radosevich, S. R. (2011): Intra and interspecific competition among invasive and native species during early stages of plant growth. Plant Ecology 212:531-542. 
[30] Maun, M. A. (1998): Adaptations of plants to burial in coastal sand dunes. - Canadian Journal of Botany 76: 713-738.

[31] McAuligge, J. R. (1994): Landscape evolution, soil formation, and ecological patterns and processes in Sonoran Desert Bajadas. - Ecological Monographs 64: 111-148.

[32] Mcintire, E. J. B., Fajardo, A. (2009): Beyond description: the active and effective way to infer processes from spatial patterns. - Ecology 90: 46-56.

[33] Nanami, S., Kawaguchi, H., Yamakura, T. (2011): Spatial pattern formation and relative importance of intra and interspecific competition in codominant tree species, Podocarpus nagi and Neolitsea aciculate. - Ecological Research 26: 37-46.

[34] Nishimura, N., Hara, T., Miura, M., Manabe, T., Yamamoto, S. (2002): Tree competition and species coexistence in a warm-temperate old-growth evergreen broad-leaved forest in Japan. - Plant Ecology 164: 235-248.

[35] Nishimura, N., Hara, T., Kawatani, M., Hoshino, D., Yamamoto, S. (2005): Promotion of species co-existence in old-growth coniferous forest through interplay of life-history strategy and tree competition. - Journal of Vegetation Science 16: 549-558.

[36] Peng, F., Wang, T., Liu, L. C., Huang, C. H. (2012): Evolution phases and spatial pattern of Nebkhas in Minqin desert-oasis ecotone. - Journal of desert research 32: 593-599. (in Chinese with an English summary).

[37] Perry, G. L. W., Enright, N. J. Miller, B. P., Lamont, B. B. (2009): Nearest-neighbor interactions in species-rich shrublands: the roles of abundance, spatial patterns and resources. - Oikos 118: 161-174.

[38] Phillips, D. L., MacMahon, J. A. (1981): Competition and spacing patterns in desert shrubs. - Journal of Ecology 69: 97-115.

[39] Pommerening, A. (2002): Approaches to quantifying forest structures. - Forestry 75: 305-324.

[40] Prentice, I. C, Werger, M. J. A. (1985): Clump spacing in a desert dwarf shrub community. - Vegetation 63: 133-139.

[41] Ripley, B. D. (1977): Modeling spatial patterns. - Journal of The Royal Statistical Society Series B-statistical Methodology 39: 172-212.

[42] Schenk, H. J., Holzapfel, C., Hamilton, J. G., Mahall, B. E. (2003): Spatial ecology of a small desert shrub on adjacent geological substrates. - Journal of Ecology 91: 383-395.

[43] Schleicher, J., Wiegand, K., Ward, D. (2011): Changes of woody plant interaction and spatial distribution between rocky and sandy soil areas in a semi-arid savanna, South Africa. - Journal of Arid Environments 75: 270-278.

[44] Schurr, F. M., Bossdorf, O., Milton, S. J., Schumacher, J. (2004): Spatial pattern formation in semi-arid shrubland: a priori predicted versus observed pattern characteristics. - Plant Ecology 173: 271-282.

[45] Sheng, J. H., Qiao, Y. X., Liu, H. Y. (2004): A study on the root system of Haloxylon Aammodendron (C. A. Mey.) Bunge. - Acta Agrestia Sinica 12: 91-94. (in Chinese with an English summary).

[46] Skarpe, C. (1991): Spatial patterns and dynamics of woody vegetation in an arid savanna. - Journal of Vegetation Science 2: 565-572.

[47] Skov, F., Svenning, J. C. (2003): Predicting plant species richness in a managed forest. Forest Ecology and Management 180: 583-593.

[48] Song, Y. Y., Li, Y. Y., Zhang, W. H. (2010): Analysis of spatial pattern and spatial association of Haloxylon ammodendron population in different developmental stages. Acta Ecologica Sinica 30: 4317-4327. (in Chinese wih an English summary).

[49] Stoll, P., Bergius, E. (2005): Pattern and process: competition causes regular spacing of individuals within plant populations. - Journal Ecology 93: 395-403.

[50] Stoyan, D., Penttinen, A. (2000): Recent applications of point process methods in forestry statistics. - Statistical Science 15: 61-78.

[51] Suding, K. N., Goldberg, D. E. (1999): Variation in the effects of vegetation and litter on recruitment across productivity gradients. - Journal Ecology 87: 436-449. 
[52] Tilman, D., Pacala, S. W. (1993): The maintenance of species richness in plant communities. In: Ricklefs R E, Schluter D (eds) Species diversity in ecological communities: historical and geographical perspectives. - University of Chicago Press, Chicago, pp 13-25.

[53] Tirado, R., Pugnaire, F. I . (2003): Shrub spatial aggregation and consequences for reproductive success. - Oecologia 136: 296-301.

[54] Wang, M., Chu, G. M. (2014): Effects of sand burial on growth and physiology of Anabasis aphylla in desert-oasis ecotone of south Junggar Basin, NW china. Environmental Protection and Sustainable Ecological Development 5: 85-92.

[55] Wang, M., Zhang, S. X., Chu, G. M. (2014): Point pattern qnalysis of different life stages of Haloxylon ammodendron in Desert-oasis ecotone of south Junggar basin. - Polish Journal of Environmental Studies 23(6): 367-373.

[56] Wang, M., Li, Y. Y., Niu, P. X., Chu, G. M. (2015): Spatial pattern formation and intraspecific competition of Aanbasis aphylla L. population in the diluvial fan of Junggar basin, NW China. - Pakistan Journal Botany 47(2): 543-550.

[57] Wang, Y., Yang, X., Shi, Z. (2013): The formation of the patterns of desert shrub communities on the western Ordos Plateau, China: the roles of seed dispersal and sand burial. - PLoS ONE 8(7): e69970.

[58] Weiner, J. (1985): Size hierarchies in experimental populations of annual plants. Ecology, 66: 743-752.

[59] Weiner, J., Damgaard, C. (2006): Size-asymmetric competition and size-asymmetric growth in a spatially explicit zone of influence model of plant competition. - Ecological Research 21: 707-712.

[60] Whitford, W. G. (2003): Ecology of desert systems. - Journal of Mammalogy 84: 11221124.

[61] Wiegand, T., Moloney, K. A. (2004): Rings, circles and null-models for point pattern analysis in ecology. - Oikos 104: 209-219.

[62] Wu, Z. Y. (1980): Vegetation of China. - Science Press, Beijing. (in Chinese).

[63] Salvati, L., Zitti, M., Ceccarelli, T. (2008): Integrating economic and environmental indicators in the assessment of desertification risk: A case study. - Applied Ecology and Environmental Research. 6: 129-138.

[64] Zhang, Y. J., Wang, Y. S. (2010): Effects of sand burial on seed germination and seedling emergence of four rare species in West Ordos area. - Acta Bot. Boreal. Occident. Sin. 30(1): 126-130.

[65] Zhang, Z. H., Hu, G., Zhu, J. D., Luo, D. H., Ni, J. (2010): Spatial patterns and interspecific associations of dominant tree species in two old-growth karst forests, SW China. - Ecological Research 25: 1151-1160.

[66] Zou, T., Li, Y., Xu, H., Xu, G. Q. (2010): Responses to precipitation treatment for Haloxylon ammodendron growing on contrasting textured soils. - Ecological Research 25: 185-194. 